\title{
Community Risk Perception and Compliance with Preventive Measures for COVID-19 Pandemic in Ethiopia
}

This article was published in the following Dove Press journal: Risk Management and Healthcare Policy

\author{
Zeleke Asnakew' \\ Kerebih Asrese ${ }^{2}$ \\ Mulusew Andualem (iD) ${ }^{3}$ \\ 'Department of Management, Bahir Dar \\ University, Bahir Dar, Ethiopia; \\ ${ }^{2}$ Department of Social Work, Bahir Dar \\ University, Bahir Dar, Ethiopia; ${ }^{3}$ School of \\ Public Health, Bahir Dar University, Bahir \\ Dar, Ethiopia
}

Correspondence: Zeleke Asnakew Tel +251911293595

Email Sirayez2013@gmail.com
Purpose: This study assessed the community's level of risk perception of COVID-19, their compliance with recommended precautionary measures, and factors that influence compliance behavior.

Methods: This study is a cross-sectional online survey administered using google forms. Data were collected from 521 respondents using various social media channels, including e-mail, Facebook, messenger, telegram, and IMO.

Results: About 9 in 10 respondents (90.4\%) perceived that they are susceptible to COVID-19. Nearly 9 in 10 participants (87.5\%) perceived that COVID-19 is a serious disease. The majority of respondents (81\%) got information about COVID-19 from television and social networking sites. The regression analyses revealed that compliance with preventive behaviors is differed by respondents' socio-demographic characteristics Being female $(\beta$ : $0.094, \mathrm{P}<0.05)$, higher perceived effectiveness of recommended preventive measures $(\beta: 0.367, \mathrm{P}<0.001)$, and higher perceived reliability of media ( $\beta$ : 0.189 , $\mathrm{P}<0.001)$ facilitated compliance with preventive measures. On the other hand, increasing age $(\beta$ : $-0.096, \mathrm{P}<0.05)$, being single $(\beta$ : $-0.127, \mathrm{P}<0.01)$, lower education level $(\beta$ : $-0.168, \mathrm{P}<0.01)$, and living at a lower administrative level were barriers to be compliant with preventive measures.

Conclusion: The majority of the respondents exercised one or more of the recommended preventive measures to avoid COVID-19 infection. Most of the respondents got information about COVID-19 from television and social networking sites. Given that about $80 \%$ of the Ethiopian population is living in rural areas without television and higher illiteracy rate to use social networking sites, concerned bodies should introduce tailored interventions to impart knowledge about COVID-19 infection and mitigating measures.

Limitations: Although the sampling procedure was random through the online system, it might not be representative to study the perception and compliance of people towards COVID-19 prevention practices at a country level due to its small size. Thus, the interpretation of the study findings needs to consider this limitation.

Keywords: COVID-19, risk perception, media exposure, compliance with prevention

\section{Introduction}

It was December 31, 2019, that the Chinese authorities reported an outbreak of pneumonia-related disease in Wuhan City to the world health organization (WHO). ${ }^{2}$ Then, the world health organization (WHO) declared the outbreak of COVID-19 as a public health emergency on January 30, 2020, when cases were discovered outside of china. ${ }^{18}$ 
On March 13, 2020, the Federal Democratic Republic of Ethiopia, Ministry of Health has confirmed a coronavirus disease (COVID-19) case in Addis Ababa, Ethiopia confirming that a 48- year-old Japanese man reported having traveled from Japan to Burkina Faso and who then arrived in Ethiopia is tested positive for COVID-19. ${ }^{4}$

Following the outbreak, the government of Ethiopia has responded to the pandemic by taking different measures. For example, the authorities have closed borders, closed schools, colleges, and universities, ordered the shuttering of nightclubs and entertainment outlets, announced social distancing measures, and called in retired and intraining medical personnel for National Health Service. In addition, all people entering Ethiopia from another country are subject to mandatory 14-day quarantine at designated hotels at the traveler's expense. Moreover, on April 8, the Prime Minister declared a state of emergency under Article 93 of the constitution, which allows it to impose more stringent measures (www.aljazeera.com/news/2020/ 04). Among them, most states have banned inter-regional public transport and public gatherings. Layoffs by private employers have also been forbidden. The international border with Djibouti remains fully open to the transport of commercial goods. In addition to the above decisions by the government, there is public health information campaign advising people to adopt hygiene measures to protect themselves and others, including more frequent handwashing with soap and water, using hand sanitizer if soap and water are not available, and covering mouth and nose with a tissue or sleeve when coughing or sneezing.

Although the government has exerted its effort to control the spread of the disease, it may not have the desired impact if a significant proportion of the population were unable or unwilling to comply with preventive measures recommended by the world health organization and the national government. Evidence indicated that in a situation where non-pharmaceutical interventions are the major preventive options, community responses are important for outbreak management during the early phase of the pandemic. ${ }^{15}$ As per our prior observation of the transmission of the disease, it is highly linked to the perceptions, and adherence of preventive mechanisms among people. The preventive mechanisms need attitudinal and behavioral change among people since most of the preventive strategies have some restrictions on human culture and daily interaction habits among the population. As a result, more people become resistant and fewer implementers in practicing those preventive strategies and victims of COVID-19. Former research findings also supported this where people who have poor knowledge; attitude and practice towards COVID-19 prevention were more affected by COVID-19. ${ }^{1}$

This cross-sectional survey is designed to assess the community's level of risk perception of COVID-19, precautionary behavior, and intention to comply with the nonpharmaceutical preventive measures as recommended by the Ethiopian government and WHO at the time of the survey. In addition, the study was designed to capture the community's perception of the effectiveness of precautionary measures recommended, and the effect of media exposure to comply with preventive measures.

In the early stage of the pandemic, the effectiveness of recommended preventive measures depends on the community's compliance. The protection motivation theory also postulates that an individual's compliance with preventive measures depends on their level of risk perception towards the current health threat. ${ }^{19}$ According to protection motivation theory, people protect themselves based on four factors to the current threat: the perceived severity of a threatening event, the perceived probability of the occurrence, or vulnerability, the efficacy of the recommended preventive behavior, and the perceived self-efficacy. ${ }^{19}$ Moreover, the level of risk perception is affected by an individual's exposure to different sources of information. ${ }^{15}$ Media was found to facilitate obtaining of up-to-date available information improving knowledge, awareness, and practices of both healthcare workers and the general public. The outbreak of the COVID-19 grabbed the attention of media news, press, and social media pages. Particularly, online health information plays a significant role in creating knowledge and awareness of people about COVID-19. ${ }^{8,11}$ However, there are too many sources and sites through which anyone can obtain information, and many of them are not credible which resulted in misinformation and difficulties to distinguish between rumors and reality.

Thus, we believe that understanding the level of risk perception, perceived efficacy of preventive measures, and the role of information exposure on compliance behavior among the general public could help in fighting against the coronavirus pandemic.

\section{Methods}

This study is a cross-sectional online survey using a questionnaire developed on google forms. To have good coverage of reaching more study participants throughout the country, various social media channels 
including e-mail, Facebook, messenger, telegram, and IMO have been used. Respondents were invited to willingly participate in the survey. To avoid duplication of responses from the same respondent, the survey tool was commanded to accept only one response from the same electronic device at any server. The study was conducted for 1-month period starting from 24 April to 24 May 2020.

\section{Survey Instrument}

The questionnaire was adapted from a survey used in a recent two studies conducted in Hong Kong and UK. ${ }^{2,15}$ The questionnaire consisted of components: sociodemographic characteristics, socioeconomic characteristics, risk perceptions towards COVID-19, perception of the effectiveness of recommended preventive measures, information exposure, perceived information reliability, and compliance with preventive measures.

\section{Socio-Demographic}

Socio-demographic characteristics consisted of sex, age, marital status.

\section{Socio-Economic}

Socio-economic status is assessed using education level, employment status, and household income.

\section{Risk Perceptions}

Risk perceptions towards COVID-19 are measured by perceived susceptibility and perceived severity. Susceptibility is measured by asking respondents about the perceived likelihood of being infected with COVID19 under the Ethiopian Government's current preventive measures as well as the perceived seriousness of COVID19. For measuring the perceived susceptibility, respondents' were asked the perceived likelihood of being infected with the coronavirus (COVID-19) at any point in the future, their families or friends will be infected with the coronavirus (COVID-19) at any point in the future or they will contract COVID-19 from families or friends and their level of worry due to COVID-19. To measure the perceived severity of COVID-19, respondents were asked to indicate their perception about the chance of having COVID-19 Cured, the chance of surviving if infected with COVID-19, the chance of having no symptoms and the chance of being in a mild condition (eg can go about daily tasks normally) in a 5-point Likert scale (from very low-very high), and the perceived seriousness of COVID19 (Very serious - not serious at all).

\section{Preventive Behaviors}

This variable consisted of three categories: (1) hygiene practices and using personal protective equipment (wearing a face mask, washing hands more frequently with soap and water, using hand sanitizer more regularly, disinfecting the home, covering nose and mouth when sneezing or coughing) (2) travel avoidance (travel to COVID-19 affected locations) (3) social distancing (avoiding social events, going to the hospital or other healthcare settings, and crowded places).

\section{Information Exposure}

This variable was measured by asking respondents the different sources of information they use about COVID19 (TV, individual social networking sites such as Facebook, Government official websites, Government agency social networking sites, magazines, newspaper) about COVID-19 and perceived information reliability was measured by asking respondents the reliability of the information they obtained from different sources (not reliable at all, least reliable, reliable, more reliable and most reliable).

\section{Data Processing and Statistical Analysis}

The collected data were exported to the Excel sheets and checked for its completeness. The excel data were exported to IBM SPSS software version 24 for further data cleaning and analysis. Data were described using frequencies and percentages. Chi-square was used to analyze the differences between categorical variables. Finally, multiple linear regression was applied to examine the effects of independent variables on compliance behavior.

\section{Results Background Characteristics of Respondents}

A total of 521 respondents have willingly completed the online survey questionnaire. Of all respondents, nearly nine in $10(88.5 \%)$ were males. As the number of females was small, we checked our data for the presence of skewness and no skewness was observed for age group, residence, and other sociodemographic variables. Our data collection and sampling was online that gave equal chance to educated people who have email and social media addresses. Thus, 
we gave an equal chance to study participants as of males; unfortunately, the number of female participants became $11.5 \%$. Thus, this sex difference was not due to the presence of confounders as a result of poor sampling and sampling procedure strategies, but it was due to chance.

Although the sample size is small to represent the actual sample size of a country-level study, the sampling method was random through an online system invitation to all Ethiopian people who can read and write and have social media account. Hence, it might have an average representation of the general population since the respondents were from different parts of the country and the process was a random selection.

Respondents' age ranged between 18 and 63 years with mean age of $34.76(\mathrm{sd} \pm 7.97)$. Seven in 10 respondents $(70.1 \%)$ are married, nearly half $(52 \%)$ are living in regional capital cities, and three in $10(16.9 \%)$ are living in the capital city of Ethiopia, Addis Ababa. More than five in 10 $(55 \%)$ respondents had a Master's degree and about two in 10 (22\%) respondents had a bachelor's degree. Seventy percent, $11 \%$, and $12 \%$ of the respondents are employed in government, private, and non-governmental organizations, respectively. More than eight in 10 respondents $(81.2 \%)$ had three or more family size (Table 1$)$.

\section{Perceived Susceptibility to COVID-19}

As indicated in Table 2, about nine in 10 respondents (90.4\%) perceived that they are susceptible to COVID19. A significantly greater proportion of married respondents than single and divorced perceived that they are susceptible to COVID $-19\left(\chi^{2}=26.425, \mathrm{p}<0.001\right)$. A greater proportion of residents in regional cities, zonal cities, and in the capital city were more likely to perceive that they are susceptible to COVID -19 than residents in the district and rural settings $\left(\chi^{2}=17.682, \mathrm{p}<0.05\right)$. Our data also indicated that respondents with a higher level of education, those who get better monthly income, and government and NGO employees were more likely to perceive that they are susceptible to COVID-19 ( $\mathrm{p}<0.01$ ). Moreover, perceived susceptibility to COVID-19 significantly increases with age $\left(\chi^{2}=15.461, \mathrm{p}<0.05\right)$. Moreover, perceived susceptibility to COVID-19 significantly increases with age $\left(\chi^{2}=15.461, \mathrm{p}<0.05\right)$ and with increasing family size $\left(\chi^{2}=12.053, \mathrm{p}<0.05\right)$.

\section{Perceived Seriousness of COVID-19}

Of all respondents who participated in the study, nearly 9 in 10 participants $(87.5 \%)$ perceived that COVID 19 is
Table I Background Characteristics of Respondents $(n=52 I)$

\begin{tabular}{|c|c|}
\hline Background Characteristics & Responses: $\mathbf{n}$ (\%) \\
\hline \multicolumn{2}{|l|}{ Sex } \\
\hline Male & $46 \mid(88.5)$ \\
\hline Female & $60(11.5)$ \\
\hline \multicolumn{2}{|l|}{ Marital status } \\
\hline Married & $365(70.1)$ \\
\hline Single & $|5|(29)$ \\
\hline Divorced & $5(1)$ \\
\hline \multicolumn{2}{|l|}{ Religion } \\
\hline Orthodox & $428(82.1)$ \\
\hline Muslim & $28(5.4)$ \\
\hline Protestant & $53(10.2)$ \\
\hline Catholic & $4(0.8)$ \\
\hline Others & $8(1.5)$ \\
\hline \multicolumn{2}{|l|}{ Residence } \\
\hline Regional cities & $27 \mid(52)$ \\
\hline Zonal towns & $|2|(23.2)$ \\
\hline District towns & $30(5.8)$ \\
\hline Addis Ababa & $88(16.9)$ \\
\hline Rural settings & $\mathrm{II}(2.1)$ \\
\hline \multicolumn{2}{|l|}{ Educational level } \\
\hline High school completed & $15(2.8)$ \\
\hline BA/BSC degree & $115(22.1)$ \\
\hline Master's degree & $288(55.3)$ \\
\hline $\mathrm{PhD}$ & $103(19.8)$ \\
\hline \multicolumn{2}{|l|}{ Income } \\
\hline$\leq 5,000 \mathrm{ETB}$ & $5 \mathrm{I}(9.8)$ \\
\hline $5,001-10,000$ ETB & $127(24.4)$ \\
\hline$>10,000$ ETB & $343(65.8)$ \\
\hline \multicolumn{2}{|l|}{ Occupation } \\
\hline Government employees & $366(70.2)$ \\
\hline Private company employees & $57(10.9)$ \\
\hline NGO employee & $64(12.3)$ \\
\hline $\begin{array}{l}\text { Others (students, unemployed, run own } \\
\text { business) }\end{array}$ & $34(6.5)$ \\
\hline \multicolumn{2}{|l|}{ Age } \\
\hline $18-29$ & $|3|(25.1)$ \\
\hline $30-39$ & 270)51.8) \\
\hline $40-49$ & $87(16.7)$ \\
\hline$\geq 50$ years & $33(6.3)$ \\
\hline \multicolumn{2}{|l|}{ Family size } \\
\hline $1-2$ & $98(18.1)$ \\
\hline $3-4$ & $212(40.7)$ \\
\hline$\geq 5$ & $211(40.5)$ \\
\hline
\end{tabular}

a serious disease. Respondents' perceptions of the seriousness of COVID-19 were found comparable in all of the background characteristics considered in the study (Table 3). 
Table 2 Background Characteristics and Perceived Susceptibility to COVID I9 (n=52I)

\begin{tabular}{|c|c|c|c|c|c|}
\hline \multirow[t]{2}{*}{ Background Characteristics } & \multicolumn{3}{|l|}{ Perceived Susceptibility } & \multirow[t]{2}{*}{$\chi^{2}$} & \multirow[t]{2}{*}{ p-value } \\
\hline & Not Susceptible n (\%) & Susceptible n (\%) & Do Not Know n (\%) & & \\
\hline Sex & & & & 0.144 & \\
\hline Male & $18(3.9)$ & $417(90.5)$ & $26(5.6)$ & & 0.931 \\
\hline Female & $2(3.3)$ & $54(90)$ & $4(6.7)$ & & \\
\hline Marital status & & & & $26.425 * * *$ & \\
\hline Married & $10(2.70$ & $345(94.5)$ & $10(2.7)$ & & 0.000 \\
\hline Single & $10(6.8)$ & $122(80.8)$ & $19(12.6)$ & & \\
\hline Divorced & - & $4(80)$ & $\mathrm{I}(20)$ & & \\
\hline Religion & & & & 10.666 & \\
\hline Orthodox & $15(3.5)$ & $388(90.7)$ & $25(5.8)$ & & 0.221 \\
\hline Muslim & $\mathrm{I}(3.6)$ & $25(89.3)$ & $2(7.1)$ & & \\
\hline Protestant & $2(3.8)$ & $48(90.6)$ & $3(5.7)$ & & \\
\hline Catholic & - & $4(100)$ & - & & \\
\hline Others & $2(25)$ & $6(75)$ & - & & \\
\hline Residence & & & & $17.682 *$ & \\
\hline Regional cities & $8(3)$ & $247(91.1)$ & $16(5.9)$ & & 0.024 \\
\hline Zonal towns & $5(4.1)$ & III(9I.7) & $5(4.1)$ & & \\
\hline District towns & $5(16.7)$ & $23(76.7)$ & $2(6.7)$ & & \\
\hline Addis Ababa & $\mathrm{I}(\mathrm{I} . \mathrm{I})$ & $81(92)$ & $6(6.8)$ & & \\
\hline Rural settings & $I(9.1)$ & $9(81.8)$ & $I(9.1)$ & & \\
\hline Educational level & & & & $17.773 *$ & \\
\hline High school completed & $I(6.7)$ & 13(86.7) & $\mathrm{I}(6.7)$ & & 0.007 \\
\hline BA/BSC degree & $5(4.3)$ & $95(82.6)$ & $15(13)$ & & \\
\hline Master's degree & $8(2.8)$ & $27 I(94.1)$ & $9(3.1)$ & & \\
\hline $\mathrm{PhD}$ & $6(5.8)$ & $92(89.3)$ & $5(4.9)$ & & \\
\hline Income & & & & $27.246 * * *$ & \\
\hline$\leq 5,000$ ETB & $2(3.9)$ & $38(74.5)$ & $\mathrm{II}(2 \mathrm{I} .6)$ & & 0.000 \\
\hline $5,00 \mathrm{I}-10,000$ ETB & $6(4.7)$ & II4(89.8) & $7(5.5)$ & & \\
\hline$>10,000$ ETB & $12(3.5)$ & $319(93)$ & $12(3.5)$ & & \\
\hline Occupation & & & & $27.463 * * *$ & \\
\hline Government employees & II (3) & $339(92.6)$ & $16(4.4)$ & & 0.000 \\
\hline Private company employees & $4(7)$ & $48(84.2)$ & $5(8.8)$ & & \\
\hline NGO employee & $4(6.3)$ & $59(92.2)$ & $\mathrm{I}(\mathrm{I} .6)$ & & \\
\hline Others & $\mathrm{I}(2.9)$ & $25(73.5)$ & $8(23.5)$ & & \\
\hline Age & & & & $\left.15.46\right|^{*}$ & \\
\hline $18-29$ years & $6(4.6)$ & $109(83.2)$ & $16(12.2)$ & & 0.017 \\
\hline 30-39 years & $\mathrm{II}(4.1)$ & $249(92.2)$ & $10(3.7)$ & & \\
\hline $40-49$ years & $2(2.3)$ & $8 I(93.1)$ & $4(4.6)$ & & \\
\hline 50 years and above & $I(3.0)$ & $32(97)$ & - & & \\
\hline Family size* & & & & $12.053^{*}$ & \\
\hline I-2 family size & $6(6.1)$ & $82(83.7)$ & $10(10.2)$ & & 0.017 \\
\hline 3-4 family size & $5(2.4)$ & 202)95.3) & $5(2.4)$ & & \\
\hline$\geq 5$ family size & $9(4.3)$ & $187(88.6)$ & $15(7.1)$ & & \\
\hline Total & $20(3.8)$ & $47 I(90.4)$ & $30(5.8)$ & & \\
\hline
\end{tabular}

Note: $* \mathrm{P}<0.05, * * * \mathrm{p}<0.001$ 
Table 3 Background Characteristics and Perceived Seriousness of COVID 19

\begin{tabular}{|c|c|c|c|c|c|}
\hline \multirow[t]{2}{*}{ Background Characteristics } & \multicolumn{3}{|c|}{ Perceived Seriousness } & \multirow[t]{2}{*}{$\chi^{2}$} & \multirow[t]{2}{*}{ p-value } \\
\hline & Not Serious n (\%) & Serious $\mathbf{n}(\%)$ & Do Not Know n (\%) & & \\
\hline Sex & & & & 3.701 & \\
\hline Male & $34(7.4)$ & $389(86.6)$ & $28(6.1)$ & & 0.157 \\
\hline Female & $\mathrm{I}(\mathrm{I} .7)$ & $57(95)$ & $2(3.3)$ & & \\
\hline Marital status & & & & 1.084 & \\
\hline Married & $24(6.6)$ & $321(87.9)$ & $20(5.5)$ & & 0.897 \\
\hline Single & $\mathrm{II}(7.3)$ & $130(86.1)$ & $10(6.6)$ & & \\
\hline Divorced & - & $5(100)$ & - & & \\
\hline Religion & & & & 14.182 & \\
\hline Orthodox & $26(6.1)$ & $382(89.3)$ & $20(4.7)$ & & 0.077 \\
\hline Muslim & $4(\mid 4.3)$ & $21(75)$ & $3(10.7)$ & & \\
\hline Protestant & $3(5.7)$ & $44(83)$ & $4(I I .3)$ & & \\
\hline Catholic & - & $4(100)$ & - & & \\
\hline Others & $2(25)$ & $5(62.5)$ & $I(12.5)$ & & \\
\hline Residence & & & & 10.795 & \\
\hline Regional cities & $13(4.8)$ & $243(89.7)$ & $15(5.5)$ & & 0.214 \\
\hline Zonal towns & $8(6.6)$ & $103(85.1)$ & $10(8.3)$ & & \\
\hline District towns & $5(16.7)$ & $25(83.3)$ & - & & \\
\hline Addis Ababa & $8(9.1)$ & $75(85.2)$ & $5(5.7)$ & & \\
\hline Rural settings & $I(9.1)$ & $10(90.9)$ & - & & \\
\hline Educational level & & & & 4.415 & 0.621 \\
\hline High school completed & $2(13.3)$ & $12(80)$ & $\mathrm{I}(6.7)$ & & \\
\hline BA/BSC degree & $9(7.8)$ & $103(89.6)$ & $3(2.6)$ & & \\
\hline Master's degree & $18(6.3)$ & $252(87.5)$ & $18(6.3)$ & & \\
\hline $\mathrm{PhD}$ & $6(5.8)$ & $89(86.4)$ & $8(7.8)$ & & \\
\hline Income & & & & 6.869 & 0.143 \\
\hline$\leq 5,000$ ETB & $4(7.8)$ & $45(88.2)$ & $2(3.9)$ & & \\
\hline $5,00 \mathrm{I}-10,000$ ETB & $14(1 \mathrm{I})$ & $108(85)$ & $5(3.9)$ & & \\
\hline$>10,000$ ETB & $17(5)$ & $303(88.3)$ & $23(6.7)$ & & \\
\hline Occupation & & & & 5.496 & 0.482 \\
\hline Government employees & $27(7.4)$ & $316(86.3)$ & $23(6.3)$ & & \\
\hline Private company employees & $\mathrm{I}(\mathrm{I} .8)$ & $53(93)$ & $3(5.3)$ & & \\
\hline NGO employee & $3(4.7)$ & $59(92.2)$ & $2(3.1)$ & & \\
\hline Others & $4(I I .8)$ & $28(82.4)$ & $2(5.9)$ & & \\
\hline Age & & & & 1.226 & 0.976 \\
\hline $18-29$ years & $10(7.6)$ & $113(86.3)$ & $8(6.1)$ & & \\
\hline $30-39$ years & $19(7)$ & $237(87.8)$ & $14(5.2)$ & & \\
\hline $40-49$ years & $4(4.6)$ & $77(88.5)$ & $6(6.9)$ & & \\
\hline 50 years and above & $2(6.1)$ & $29(87.9)$ & $2(6.1)$ & & \\
\hline Family size* & & & & 2.652 & 0.618 \\
\hline I-2 family size & $8(8.2)$ & $85(86.7)$ & $5(5.1)$ & & \\
\hline 3-4 family size & $14(6.6)$ & 189(89.2) & $9(4.2)$ & & \\
\hline$\geq 5$ family size & $13(6.2)$ & $182(86.3)$ & $16(7.6)$ & & \\
\hline Total & $35(6.7)$ & $456(87.5)$ & $30(5.8)$ & & \\
\hline
\end{tabular}




\section{Source of Information About COVID-19}

Respondents were asked their source of information about the status of COVID-19 and the means of prevention methods to reduce the risk of COVID-19 infection. The majority of respondents, $81 \%, 80 \%, 64.5 \%$, and $64.3 \%$ reported that they got information about COVID-19 from television, social networking sites (Facebook, telegram, etc.), health professionals, and government social media pages, respectively. Of all sources of information assessed, magazines (26\%) and newspapers $(29 \%)$ were the list source of information about COVID-19 reported by respondents (Figure 1).

\section{Compliance with Prevention Measures}

The government of Ethiopia and concerned stakeholders are communicating different precaution measures to avoid COVID-19 infection and lessen losses attributed to the pandemic. ${ }^{14}$ Thus, respondents were asked about their compliance with these precaution measures as a perceived benefit of the exercises. As indicated in Figure 2, almost all respondents $(97.1 \%)$ washed their hands with soap and water. The majority, $87.5 \%, 81.9 \%, 80 \%$, and $87 \%$ of the respondents avoid social events, visiting healthcare facilities, public transport, and washed their hands, respectively. Similarly, nine in 10 respondents $(91 \%)$ used hand sanitizers and cover their noses and mouth while coughing or sneezing. Slightly more than half of the respondents $(56.5 \%)$ wore face masks when going out of home and only $46.9 \%$ disinfected their home.

\section{Factors Associated with Compliance of Preventive Behavior}

One of the objectives of this study was to assess the factors that facilitate or deter compliance with COVID-19 preventive behavior. The multiple linear regression analysis results in Table 4 revealed that respondents' compliance with preventive measures significantly differed by genders, perceived effectiveness of recommended measures, perceived reliability of media, education levels, marital status, and residence. Females compared to males ( $\beta$ : 0.094, $\mathrm{P}<0.05$ ), respondents with higher perceived effectiveness of recommended preventive measures $(\beta: 0.367, \mathrm{P}<0.001)$, those with higher perceived reliability of media ( $\beta$ : 0.189 , $\mathrm{P}<0.001$ ) showed significantly higher compliance with preventive measures. On the other hand, increasing age ( $\beta$ : $-0.096, P<0.05)$, respondents with bachelor's degree or lower $(\beta$ : $-0.168, \mathrm{P}<0.01)$, those living at zonal cities compared to regional city residents $(\beta$ : $-0.144, \mathrm{P}<0.001)$, district residents compared to regional city residents ( $\beta$ : $-0.107, \mathrm{P}<0.01$ ), rural residents compared to regional city $(\beta$ : $-0.101, P<0.01)$, single compared to married $(\beta$ : $-0.127, \mathrm{P}<0.01)$, had significantly lower compliance with preventive measures. All the variables together explained $36.4 \%$ of the variation in compliance behavior.

\section{Discussion}

This study assessed the community's level of risk perception of COVID-19 and their compliance with recommended precautionary measures. The majority of respondents $(90.4 \%)$ perceived that they are susceptible to COVID-19. Nearly nine in 10 respondents (87.5\%) perceived that COVID-19 is a serious disease. Married respondents perceived that they are more susceptible than single respondents. A possible reason for this finding may be that married respondents might have family members within the household who may have differential exposure outside the home; thus, they may feel that

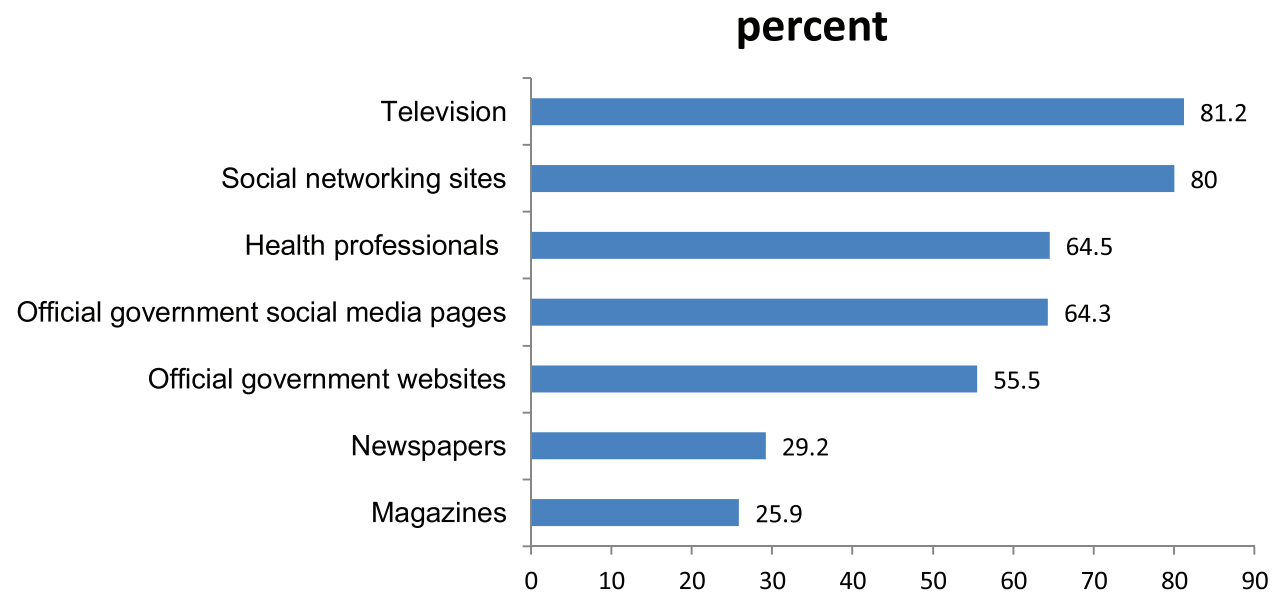

Figure I Percentage distribution of respondents by their source of information about COVID-19. 


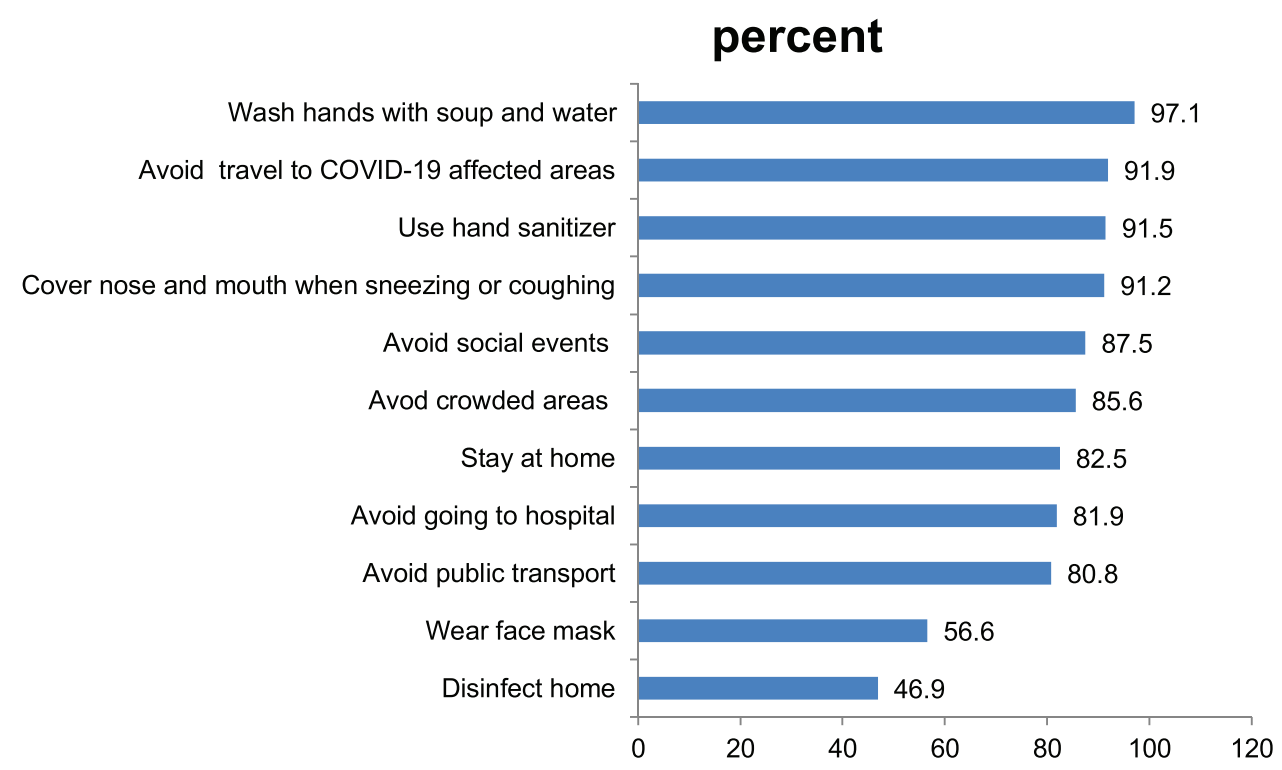

Figure 2 Distribution of respondents by types of prevention measures exercised.

one of the family members may get infected and transmit to the other embers. Our data also indicated that a greater proportion of residents in regional cities, zonal cities, and in the capital city were more likely to perceive that they are susceptible to COVID 19 than residents in the district and rural settings.

This finding is consistent with a report in Myanmar $^{17}$ reporting that perceived susceptibility to COVID-19 was

Table 4 Result of Multiple Linear Regression on Factors Associated with Compliance Behavior

\begin{tabular}{|c|c|c|c|c|c|}
\hline \multicolumn{6}{|l|}{ Coefficients } \\
\hline & \multicolumn{2}{|c|}{$\begin{array}{l}\text { Unstandardized } \\
\text { Coefficients }\end{array}$} & \multirow{2}{*}{$\begin{array}{l}\text { Standardized Coefficients } \\
\text { Beta }\end{array}$} & \multirow[t]{2}{*}{$\mathbf{t}$} & \multirow[t]{2}{*}{ Sig. } \\
\hline & B & Std. Error & & & \\
\hline (Constant) & 6.666 & 3.204 & & 2.081 & 0.038 \\
\hline Sex (female vs male) & 2.165 & 0.853 & 0.094 & 2.540 & 0.011 \\
\hline Number of families & 0.096 & 0.158 & 0.023 & 0.606 & 0.545 \\
\hline Age & -.088 & 0.045 & -.096 & -1.970 & 0.049 \\
\hline Perceived seriousness & 0.168 & 0.140 & 0.044 & 1.197 & 0.232 \\
\hline Perceived susceptibility & 0.197 & 0.133 & 0.055 & 1.482 & 0.139 \\
\hline Media exposure & 0.241 & 0.055 & 0.189 & 4.409 & 0.000 \\
\hline Perceived effectiveness of prevention methods & 0.382 & 0.044 & 0.367 & 8.770 & 0.000 \\
\hline $\mathrm{MSc} / \mathrm{MA}$ vs $\mathrm{PhD}$ & -1.349 & 0.735 & -.091 & -1.835 & 0.067 \\
\hline $\mathrm{BSc} / \mathrm{BA}$ vs $\mathrm{PhD}$ & -2.972 & 0.989 & -.168 & -3.004 & 0.003 \\
\hline High school vs PhD & 3.004 & 1.678 & 0.068 & 1.790 & 0.074 \\
\hline Zonal vs regional city & -2.504 & 0.665 & -.144 & -3.766 & 0.000 \\
\hline District vs regional city & -3.390 & 1.194 & -.107 & -2.838 & 0.005 \\
\hline Capital city vs regional & 0.568 & 0.762 & 0.029 & 0.746 & 0.456 \\
\hline Rural vs regional city & -5.149 & 1.917 & -.101 & -2.686 & 0.007 \\
\hline ONGO vs Govt employee & -.132 & 0.854 & -.006 & -.155 & 0.877 \\
\hline Private vs Govt employee & -.644 & $0.88 I$ & -.027 & -.732 & 0.465 \\
\hline Single vs married & -2.059 & 0.718 & -.127 & -2.867 & 0.004 \\
\hline
\end{tabular}

Notes: Model summary: No of observations $=521, R^{2}=364, \Delta R^{2}=341, F=15.944, p<000$ 
higher among people who are living in crowded places. In Ethiopia, urban centers and cities have crowded residents.

In the current study, respondents with a higher level of education, better monthly income, and employment were more likely to perceive that they are susceptible to COVID-19. The majority of the respondents more often used television (81\%), social networking sites (80\%), health professionals $(64.5 \%)$, and government social media pages $(64.3 \%)$ to get information about the epidemic. Thus, these groups of people may have better access to information from different sources. In addition, as a means to limit the spread of the disease, there was a lockdown time and state of emergency issued by the government. These initiatives taken by the government and the better access to information may increase the groups' understanding of the causes and consequences of the disease so that they may perceive that they are susceptible to the COVID-19. A study from Iran ${ }^{9}$ supported this finding where lower educated people had a low level of knowledge and poorer practices towards COVID-19.

Consistent with other studies, ${ }^{5-7}$ perceived susceptibility to COVID-19 is significantly associated with increasing age. Particularly the study by ${ }^{7}$ reported that perceived risk to COVID-19 increased by $4.9 \%$ for every one-year increase in age among the Chinese population. This increased susceptibility to COVID-19 with increasing age may be due to the decreased immunity status with increased age that makes people more susceptible to acquire infections of both communicable and noncommunicable types or because of the information shared by the global community that elders are more susceptible to be victims of COVID-19 than the youth due to other comorbidities. Recent evidence also indicated that people with comorbidities are at the highest risk of getting COVID-19 compared to the rest of the population. ${ }^{9,17}$

Our finding that perceived susceptibility to COVID-19 increased with increasing family size corroborates to a study in China $^{7}$ reporting people living with families including children had a higher perceived risk level to COVID-19. A study in Jordan ${ }^{12}$ also reported that having children was reported as a perceived risk to acquire COVID-19. This might be related to the family income that challenged them to access the recommended protective equipment, proper nutrition, and cover costs of medical care to the larger family sizes. In addition, as family size increases, they might move to more places including the markets and other crowded places while performing their daily routines to feed the larger family size. This condition might expose them to COVID-19.

The Ethiopian government and other stakeholders are engaging in imparting different prevention measures for citizens to lessen the spread of COVID-19 in the country. Our results indicated that respondents are exercising one or more of the prevention measures. Of the different measures assessed in this study, wearing a face mask (56.5\%) was the least practice prevention measures by the respondents, even so, wearing face mask practice in our study is better than the findings reported in South West Ethiopia ${ }^{14}$ where only $14 \%$ of the respondents reported wore a face mask to prevent COVID-19. Moreover, avoiding participation in social events, avoiding visiting health care facilities, avoiding public transport, and washing hands with soap and water frequently as prevention measures are better practiced among our respondents than reported in South West Ethiopia, ${ }^{14}$ but consistent with the study conducted in Kenya. ${ }^{3,13}$ These observed differences in practicing prevention measures might be differences in enforcing the implementation of these activities. The differences might be also possible due to the participants of the study. In our study, the majority of study participants are with higher education levels $(96.2 \%)$ that could practice the prevention measures through the recommended procedures.

The analyses of factors predicting compliance with preventive measures identified different individual and socio-economic factors that facilitate or deter the behavior. This study revealed that females were more likely to have better compliance with preventive behavior than their male counterparts. This result is consistent with studies conducted in other parts of the world ${ }^{16}$ reporting that females showed more compliance behavior with recommended COVID-19 preventive measures such as more frequent washing their hands, covering their nose and mouth when sneezing and coughing, kept social distancing with others, staying at home, avoid using public transportation and frequently disinfecting touched surfaces.

Based on our data analysis, compliance with COVID19 preventive strategies was varied by gender, education level, and residence of study participants. Respondents with a lower level of education were found less likely to be compliant with preventive behaviors. A similar finding was reported by a recent study in Iran where lower education was a factor in low knowledge and preventive practice towards COVID-19. ${ }^{10}$ The low education level might limit people's access to information through various means or 
may limit the information source on COVID-19 to exercise various prevention measures. On the other hand, females, better educated and urban residents had better compliance compared to the counterpart study participants. This implies that males, less educated and rural residences are at a higher risk of getting COVID-19 infection. This is a serious situation to acquire and transmit COVID-19 since most of the Ethiopian populations are non-PhD holders, over $85 \%$ of the population is living in rural settings, and males are outdoors and movable than females. Thus, these findings are important for policymakers to reconsider and support the preventive strategies of COVID-19. Participating females in mobilizing the community with the practice of preventive mechanisms might be effective to make awareness creation among the large population since they can demonstrate them through their life experience. Similarly, $\mathrm{PhD}$ level educated people are respected and believed to be knowledgeable by most of the community members in Ethiopia. Thus, making them among the COVID-19 prevention, awareness creation, community mobilizers and keynote speakers, and evidence generating team members could benefit the policymakers and COVID-19 programs at large. Moreover, the findings indicated the need to have more prevention, mobilization and accessing preventive equipment towards the rural community. Therefore, policy-makers and COVID019 prevention programs might be benefited from these findings to revise their anti-COVID-19 strategies for evidencebased targeted interventions and wise resource allocations.

As the source of COVID-19 information (how the disease spreads and prevention measures) for the majority of the respondents in this study are television and social networking sites, the availability and accessibility of these channels are limited in the remote settings and rural areas. Thus, the lower urban areas and rural residents may be less compliance with preventive measures because of limited access to information about the types of protective measures in these remote settings, the unavailability of protective equipment, or the misconception that COVID-19 is a disease mainly observed in cities and metropolitans where people are overcrowded (World Health Organization, 2020). While increasing age positively associated with increased perceived susceptibility to COVID-19 in the bivariate analyses, increasing age decreased compliance with the practice of preventive measures in the multivariate analyses. The findings indicated that the increased perception of susceptibility did not bring a commensurate behavior of compliance with protective measures. Future research may unveil the reasons for these discordant findings.

This study has several limitations that should be acknowledged. Although the sampling procedure was random through the online system, it might not be representative to study the perception and compliance of people towards COVID-19 prevention practices at a country level due to its small size. Thus, the interpretation of the study findings needs to consider this limitation. There is an overrepresentation of educated health-conscious individuals and those more informed or concerned about the outbreak. Furthermore, with the stay at the home recommendation and emergency state in place, such an educated group of the population confined to their homes has turned to social media and other web-based platforms for social communication. Under this exceptional context, members of the general public who normally would not participate in surveys may be more likely to participate given the media attention, severity, and the outbreak's large impact on many aspects of daily life. Even so, this study provides important information on the extent of peoples' practice of recommended preventive measures and facilitators and barriers to compliance with preventive measures.

\section{Conclusions}

The finding of our study has several implications for decision-making. It has indicated that the majority of the respondents exercised one or more of the recommended preventive measures to avoid COVID-19 infection. Our findings also indicated that people residing in lower urban centers and rural areas were less likely to practice prevention measures than respondents in regional cities. Most of the respondents got information about COVID-19 from television and social networking sites. The availability and accessibility of these channels are limited in the remote settings and rural areas. Thus, the lower urban areas and rural residents may be less compliance with preventive measures because of limited access to information about the types of protective measures in these remote settings, the unavailability of protective equipment, or the misconception that COVID-19 is a disease mainly observed in cities and metropolitans where people are overcrowded. While increasing age positively associated with increased perceived susceptibility to COVID-19 in the bivariate analyses, increasing age decreased compliance with the practice of preventive measures in the multivariate analyses. The findings indicated that the increased perception of susceptibility did not bring a commensurate behavior of 
compliance with protective measures. On the other hand, perceived effectiveness of recommended precaution measures is positively associated with compliance behavior.

\section{Ethics and Consent}

The study was conducted according to the principles of the Declaration of Helsinki and fulfilled the requirements of Ethiopian National Health Research and Ethics Guideline. Moreover, the study received ethical approval from Ethical Review Committee of Bahir Dar University. Information and informed consent sheet were sent to each study participant together with the questionnaire. Consequently, data were collected after getting their informed consent from each study participant. Participation was fully voluntary based including not responding after reading the instructions and questions. Data confidentiality was maintained through anonymity by avoiding any personal identifiers. Since data collection was online through a log-in system, the process was secured.

\section{Disclosure}

The authors declare that they have no conflicts of interest.

\section{References}

1. Asemahagn MA. Factors determining the knowledge and prevention practice of healthcare workers towards covid-19 in amhara region, ethiopia: a cross-sectional survey. Trop Med Health. 2020;48:1-11. doi:10.1186/s41182-020-00254-3

2. Atchison CJ, Bowman L, Vrinten C, et al. Perceptions and behavioural responses of the general public during the covid-19 pandemic: a cross-sectional survey of UK adults. medRxiv. 2020.

3. Austrian K, Pinchoff J, Tidwell JB, et al. 'Covid-19 related knowledge, attitudes, practices and needs of households in informal settlements in Nairobi, Kenya'. LANCET. 2020. doi:10.2139/ssrn.3576785

4. Baye K. Covid-19 Prevention Measures in Ethiopia: Current Realities and Prospects. Intl Food Policy Res Inst; 2020:141.

5. Wändi bruine de bruin, 'age differences in covid-19 risk perceptions and mental health: evidence from a national us survey conducted in March 2020'. The Journals of Gerontology: Series B. 2020.

6. Cvetković VM, Nikolić N, Nenadić UR, Öcal A, Noji EK, Zečević M. Preparedness and preventive behaviors for a pandemic disaster caused by covid-19 in Serbia. Int J Environ Res Public Health. 2020;17:4124. doi:10.3390/ijerph17114124

Risk Management and Healthcare Policy

\section{Publish your work in this journal}

Risk Management and Healthcare Policy is an international, peerreviewed, open access journal focusing on all aspects of public health, policy, and preventative measures to promote good health and improve morbidity and mortality in the population. The journa welcomes submitted papers covering original research, basic science, clinical \& epidemiological studies, reviews and evaluations,
7. Shan H, Chen S, Kong L, Liu W. Analysis of risk perceptions and related factors concerning covid-19 epidemic in Chongqing, China. $J$ Community Health. 2020;1-8.

8. Hernández-García I, Giménez-Júlvez T. Assessment of health information about covid-19 prevention on the internet: infodemiological study. JMIR Public Health Surveillance. 2020;6:e18717. doi:10.2196/ 18717

9. Honarvar B, Lankarani KB, Kharmandar A, Shaygani F, Zahedroozgar M. Knowledge, attitudes, risk perceptions, and practices of adults toward covid-19: a population and field-based study from Iran. Int J Public Health. 2020;1-9.

10. 'Knowledge, Attitudes, Risk Perceptions, and Practices of Adults toward Covid-19. A population and field-based study from Iran'. Int J Public Health. 2020;65:731-739. doi:10.1007/s00038-02001406-2

11. Jayasinghe R, Ranasinghe S, Jayarajah U, Seneviratne S. Quality of online information for the general public on covid-19'. Patient Educ Couns. 2020;103:2594-2597. doi:10.1016/j.pec.2020.08.001

12. Karasneh R, Al-Azzam S, Muflih S, Soudah O, Hawamdeh S, Khader Y. Media's effect on shaping knowledge, awareness risk perceptions and communication practices of pandemic covid-19 among pharmacists'. Res Social Administrative Pharmacy. 2020. doi:10.1016/j.sapharm.2020.04.027

13. Karijo E, Wamugi S, Lemanyishoe S, et al. Knowledge, attitudes, practices, and the effects of covid-19 on health seeking behaviors among young people in Kenya. BMC, Public health. 2020.

14. Kebede Y, Yitayih Y, Birhanu Z, Mekonen S, Ambelu A. Knowledge, perceptions and preventive practices towards covid-19 early in the outbreak among jimma university medical center Visitors, Southwest Ethiopia. PLoS One. 2020;15:e233744. doi:10.1371/journal. pone. 0233744

15. Kwok KO, Li KK, Chan HH, et al. Community responses during the early phase of the covid-19 epidemic in hong kong: risk perception, information exposure and preventive measures. MedRxiv. 2020.

16. Siyue L, Feng B, Liao W, Pan W. Internet use, risk awareness, and demographic characteristics associated with engagement in preventive behaviors and testing: cross-sectional survey on covid-19 in the United States'. J Med Internet Res. 2020;22:e19782. doi:10.2196/ 19782

17. Mya Kyaw S, Aye SM, Hlaing Win A, Hlaing Su S, Thida A, 'Awareness, perceived risk and protective behaviours of myanmar adults on covid-19'; 2020. Available from: https://www.ijcmph.com/ index.php/ijcmph/article/download/6308/3908.

18. World Health Organization, 'Rolling updates on coronavirus disease (covid-19)'. Recuperado de; 2020. Available from: https://www.who. int/emergencies/diseases/novel-coronavirus-2019/events-as-theyhappen.

19. Rogers RW, Prentice-Dunn S. Protection motivation theory. 1997. 